\title{
Relationship of Secondary School Mathematics Achievement with Engineering Mathematics 2 in Polytechnics
}

\author{
Husnira Binti Hussin ${ }^{1 *}$, Marina binti Majid ${ }^{2}$, Rohayu binti Ab Wahab ${ }^{3}$ \\ ${ }^{123}$ Politeknik Sultan Mizan Zainal Abidin \\ $\risingdotseq$ e-mail: husnira@psmza.edu.my
}

\begin{abstract}
Engineering Mathematics 2 is one of the core courses for all diploma-level engineering students in Malaysian Polytechnic. From the statistics obtained, students achievement in the Engineering Mathematics 2 course (DBM2013) is still moderate and less satisfactory. This is because the subject of Engineering Mathematics 2 is mostly related to calculus and only students who have taken Additional Mathematics subject during secondary school had a basic in the Engineering Mathematics 2. Thus, this research was developed to see the relationship and influence of Mathematics subject during secondary school level, especially Additional Mathematics with the subject of Engineering Mathematics 2 in Polytechnic. High school achievement was measured using the Sijil Pelajaran Malaysia (SPM) examination results in Additional and Modern Mathematic subjects. Meanwhile, the results in the polytechnic level were measured from the final result of the Engineering Mathematics 2 course. The research used secondary data obtained from the examination unit from 2442 students of Semester 2 of Diploma in Civil Engineering (JKA), Diploma in Electrical Engineering (JKE) and Diploma in Mechanical Engineering JKM) at Polytechnic Sultan Mizan Zainal Abidin (PSMZA). Data obtained were processed and analyzed using Microsoft Excel 2010 and Statistical Packages For Social Sciences (SPSS) version 23.0 through Easy Linear Regression Analysis. The findings from the regression analysis showed that there was a significant positive correlation between the achievement of Mathematics during secondary schools with the achievement of Engineering Mathematics 2 in polytechnics and it also proved that Additional Mathematics is one of the medium for student's excellence in Engineering Mathematics 2 at polytechnics.
\end{abstract}

Keywords:; Polytechnic; Modern Mathematics; Additional Mathematics; Engineering Mathematics 2

\section{Hubungan Pencapaian Matematik Sekolah Menengah dengan Matematik Kejuruteraan 2 di Politeknik}

\footnotetext{
Abstract

Kejuruteraan Matematik 2 adalah salah satu kursus teras untuk semua pelajar kejuruteraan peringkat diploma di Politeknik Malaysia. Daripada statistik yang diperoleh, pencapaian pelajar dalam kursus Kejuruteraan Matematik 2 (DBM2013) masih sederhana dan kurang memuaskan. Ini kerana subjek Kejuruteraan Matematik 2 kebanyakannya berkaitan dengan kalkulus dan hanya pelajar yang mengambil mata pelajaran Matematik Tambahan semasa sekolah menengah
} 
mempunyai asas dalam Matematik Kejuruteraan 2. Oleh itu, kajian ini telah dibangunkan untuk melihat hubungan dan pengaruh subjek Matematik semasa peringkat sekolah menengah, terutamanya Matematik Tambahan dengan mata pelajaran Kejuruteraan Matematik 2 di Politeknik. Pencapaian sekolah tinggi diukur menggunakan keputusan peperiksaan Sijil Pelajaran Malaysia (SPM) dalam mata pelajaran tambahan dan Matematik Moden. Sementara itu, keputusan di peringkat politeknik diukur dari hasil akhir kursus Kejuruteraan Matematik 2. Penyelidikan menggunakan data sekunder yang diperolehi dari unit peperiksaan dari 2442 pelajar Semester 2 Diploma Kejuruteraan Awam (JKA), Diploma Kejuruteraan Elektrik (JKE) dan Diploma Kejuruteraan Mekanikal JKM) di Politeknik Sultan Mizan Zainal Abidin (PSMZA). Data yang diperoleh telah diproses dan dianalisis dengan menggunakan versi Microsoft Excel 2010 dan Pakej Statistik untuk Sains Sosial (SPSS) versi 23.0 melalui Analisis Regresi Talian Mudah. Penemuan dari analisis regresi menunjukkan terdapat korelasi positif yang signifikan antara pencapaian Matematik semasa sekolah menengah dengan pencapaian Matematik Kejuruteraan 2 di politeknik dan juga membuktikan bahawa Matematik Tambahan adalah salah satu medium untuk kecemerlangan pelajar dalam Kejuruteraan Matematik 2 di politeknik.

Keywords:Spm; Politeknik; Matematik moden; Matematik Tambahan; Matematik Kejuruteraan 2

\section{PENGENALAN}

Politeknik Sultan Mizan Zainal Abidin mempunyai tujuh program Kejuruteraan iaitu Diploma Kejuruteraan awam (DKA), Diploma Kejuruteraan Mekanikal (DKM), Diploma Kejuruteraan Automotif (DAD), Diploma Kejuruteraan Mekatronik (DEM), Diploma Kejuruteraan Pembuatan (DTP), Diploma Kejuruteraan Elektrik \& Elektronik (DEE), Diploma Kejuruteraan Elektrik (Komunikasi) dan Diploma Kejuruteraan Elektronik Komputer (DTK).

Politeknik telah menawarkan kursus Matematik Kejuruteraan 2 (DBM2013) yang merupakan kursus wajib bagi semua program Kejuruteraan. Kursus ini merupakan prasyarat untuk mengambil kursus Engineering Mathematics 3 pelajar Kejuruteraan Mekanikal dan pelajar Kejuruteraan Elektrik. Sukatan kursus ini telah mendapat pengiktirafan dari Malaysian Qualification Accredition (MQA) sebelum digunapakai di seluruh politeknik di Malaysia. Matematik Kejuruteraan 2 mempunyai tiga topik yang utama iaitu eksponen \& logaritma, pembezaan dan pengamiran.

Sukatan kursus tersebut adalah asas pengajaran bagi kursus yang khusus untuk setiap program. Sebagai kursus asas sewajibnya pelajar perlu mahir terlebih dahulu, untuk pergi lebih jauh dalam bidang program mereka. Namun terdapat persoalan yang timbul sejauh mana pelajar mampu mencapai kecemerlangan dalam kursus ini. Kursus Matematik ini wajib dikuasai oleh pelajar kerana setiap cabang kerjaya banyak menggunakan aplikasi Matematik dalam bidang masing-masing. Sebagai contoh, bidang Kejuruteraan banyak menggunakan pengetahuan asas yang mendalam dalam kursus Matematik.

Pencapaian pelajar yang rendah dalam kursus Matematik mesti diambil perhatian yang serius. Pencapaian yang rendah ini boleh menjejaskan pembelajaran pelajar jika tidak dibendung lebih awal di mana ianya boleh mengakibatkan permasalahan yang akan timbul dalam program yang mereka ambil khususnya bidang Kejuruteraan. Pembelajaran Matematik seringkali dianggap sebagai sesuatu yang sukar dan membosankan bagi sesetengah pelajar. Kesan daripada itu, lahirlah pelajar yang tiada keyakinan diri dalam menyelesaikan masalah Matematik samada dalam bidang akademik mahupun dalam kehidupan seharian.

\section{Objektif Kajian}


Mengenalpasti sejauhmana hubungan dan pengaruh matapelajaran Matematik tambahan dan Matematik moden di sekolah menengah terhadap pencapaian pelajar dalam kursus Matematik Kejuruteraan 2 di politeknik.

\section{Pernyataan Masalah}

Sebagaimana yang diketahui, syarat kemasukan Politeknik Malaysia untuk program Kejuruteraan hanya mewajibkan kepujian dalam Matematik moden sahaja di peringkat SPM. Berdasarkan portal pengambilan pelajar politeknik, syarat kemasukan program Kejuruteraan di politeknik malaysia adalah warganegara malaysia, lulus Bahasa Melayu, lulus Sejarah, lulus Bahasa Inggeris dan mendapat tiga kepujian dalam mata pelajaran lain. Manakala silibus Matematik Kejuruteraan 2 pula mengandungi topik indek dan logaritma, pembezaan dan pengamiran. Ketiga-tiga topik ini hanya dipelajari dalam matapelajaran Matematik tambahan sahaja semasa di sekolah menengah.

Daripada pemerhatian yang dilakukan oleh pensyarah, didapati pelajar agak sukar untuk menguasai topik-topik dalam kursus DBM2013 ini kerana ianya agak susah dan kemungkinan juga disebabkan ketiadaan asas yang kukuh. Kursus DBM 2013 juga merupakan kursus yang wajib dilepasi oleh semua pelajar Politeknik dan menjadi pra syarat utama untuk pelajar mengambil Matematik Kejuruteraan 3 pada semester berikutnya. Namun terdapat segelintir pelajar yang gagal dalam kursus tersebut. Kegagalan mereka ini menyebabkan mereka perlu mengulang pada semester berikutnya sehingga mendatangkan kesan-kesan yang negatif terhadap pelajar. Implikasi daripada masalah ini ialah pelajar akan mengalami gangguan dalam penyusunan jadual program asal mereka. Antara masalah yang sering berlaku ialah pertindihan jadual waktu antara kursus yang di ulang dengan kursus yang wajib di ambil dalam semester berikutnya. Akibatnya wujud pelajar yang terpaksa menamatkan pengajian melebihi tempoh masa yang ditetapkan.

Mungkin terdapat pelbagai faktor kegagalan pelajar tersebut, namun wujud tanggapan bahawa pelajar yang gagal atau mendapat keputusan yang kurang cemerlang dalam Matematik Kejuruteraan 2 mungkin disebabkan oleh prestasi yang kurang baik dalam matapelajaran Matematik terutamanya Matematik tambahan di sekolah menengah. Oleh itu, kajian statistikal ini dilaksanakan untuk melihat sejauhmana tanggapan tersebut benar dengan melihat hubungan signifikan yang akan diperolehi bagi mengenalpasti langkah-langkah yang boleh diambil untuk membantu pelajar-pelajar yang lemah ini.

\section{Skop kajian}

Kajian ini hanya melibatkan data pelajar Kejuruteraan semester dua yang mengambil kursus Matematik Kejuruteraan 2 di Politeknik Sultan Mizan Zainal Abidin. Data juga meliputi keputusan matematik tambahan dan matematik moden pelajar tersebut semasa SPM. Sesi yang terlibat ialah Jun 2016, Disember 2016, Jun 2017 dan Disember 2017 bagi Jabatan Kejuruteraan Awam, Kejuruteraan Elektrik dan Kejuruteraan Mekanikal. Analisis yang digunakan ialah analisi korelasi dan regresi linear mudah.

\section{LITERATUR REVIEW}

Matematik Tambahan merupakan mata pelajaran elektif yang ditawarkan kepada pelajar sekolah menengah yang mengambil aliran sains tulen. Pelajar mempunyai kebebasan memilih matapelajaran tersebut mengikut minat dan kebolehan pelajar sendiri. Mengikut kandungan kurikulum Matematik Tambahan, tujuan utamanya adalah menyediakan pelajar yang mengikuti pelajaran Matematik di peringkat pasca Sijil Pelajaran Malaysia (SPM). Penguasaan konsep-konsep dalam kandungan kurikulum Matematik Tambahan sangat penting bagi membantu pelajar menguasai konsep-konsep Matematik yang berperingkat lebih tinggi dan kompleks apabila mereka melanjutkan pelajaran mereka di institusi pengajian tinggi (Wong Jin Kae,2010). 
Faktor latar belakang diri, tenaga pengajar dan kondisi tempat pengajian mempengaruhi pencapaian pelajar dalam kursus Matematik dan statistik manakala kaedah pembelajaran berpusatkan pelajar adalah lebih diminati oleh pelajar berbanding pembelajaran berpusatkan guru (Siti Nor Asyikin et al,). Tahap penguasaan Matematik di peringkat menengah sangat mempengaruhi pencapaian pelajar di kolej atau Universiti. Pelajar yang mempunyai latar belakang Matematik tambahan yang cemerlang di peringkat menengah menyumbangkan pencapaian yang baik di peringkat kolej dan universiti.

Bidang teknikal dan perdagangan memerlukan pelajar mempunyai kemahiran Matematik yang sesuai digunakan dalam lapangan kerja masing-masing (Siti Huzaifah et al, 2017). Namun bagi pelajar teknikal ini mereka beranggapan bahawa bidang pekerjaan mereka tidak memerlukan kemahiran Matematik yang tinggi berbanding kemahiran kerja yang lain. Justeru itu mereka tidaklah menetapkan sasaran untuk cemerlang dalam Matematik sekadar memperolehi gred kepujian untuk meneruskan pengajian. Sedangkan bidang Kejuruteraan bukan sahaja memerlukan pengetahuan yang tinggi dalam kursus berkaitan fizik malahan juga pengetahuan asas yang mendalam dalam Matematik.

Pencapaian pelajar di peringkat SPM bagi matapelajaran fizik dan Matematik tambahan mempengaruhi pencapaian akademik mereka dalam bidang Kejuruteraan di peringkat Diploma (Titi khawa dan BIBI, 2000). Oleh yang demikian penekanan terhadap Matapelajaran fizik dan Matematik tambahan merupakan syarat utama memasuki bidang Kejuruteraan adalah jelas.

Kursus Matematik seperti Kalkulus, Aljabar dan Statistik menjadi kursus teras dalam kebanyakan program pengajian yang ditawarkan di institusi pengajian tinggi di Malaysia. (Safura \& Norziah,2015) Kajian oleh Ahmad Fauzi, Norhayati dan Wong (2005) mendapati bahawa terdapat hubungan yang kuat antara pencapaian pelajar dalam Matematik dan Matematik Tambahan pada peringkat Sijil Pelajaran Malaysia (SPM) dengan pencapaian pelajar di peringkat universiti bagi matapelajaran Kalkulus. Pelajar peringkat diploma yang dikaji memiliki minat yang berbeza terhadap Kalkulus dengan peratusan pelajar yang tidak menunjukkan minat yang positif terhadap Kalkulus adalah tinggi. Pelajar yang memperoleh gred yang baik dalam Matematik Tambahan juga didapati kurang menghadapi masalah dalam menguasai Kalkulus pada peringkat pengajian tinggi. Pengetahuan dan pengalaman mempelajari bab Pembezaan dan Pengamiran sebelum ini sedikit sebanyak telah membantu pelajar memahami Kalkulus pada peringkat pengajian tinggi dengan lebih baik.

\section{METODOLOGI}

Metodologi kajian ialah merangkumi cara, kaedah dan pendekatan yang digunakan untuk mencapai matlamat dan objektif kajian. Metodologi kajian yang dirancang akan membantu proses kajian dijalankan dengan lebih sistematik dan berkesan bagi mendapatkan hasil yang diinginkan. Metodologi kajian dan strategi yang disusun untuk mendapatkan data dan maklumat untuk mencapai objektif dan matlamat kajian seperti yang dijelaskan dalam Rajah 1. 


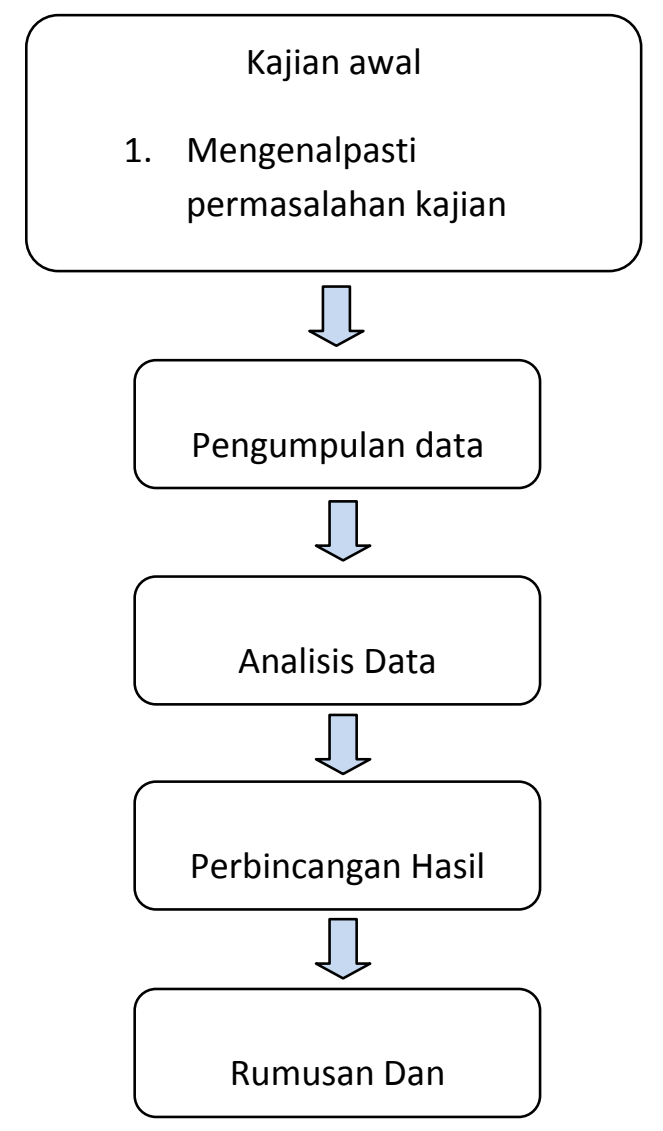

Rajah 1 : Carta alir proses kajian yang dijalankan.

\section{Rekabentuk Kajian}

Kajian yang dijalankan ini merupakan satu kajian kualitatif yang menggunakan data sekunder yang diperolehi daripada unit peperiksaaan PSMZA. Proses pengasingan dan pengkodan data dijalankan menggunakan Microsoft Excell 2010 dan kemudian diproses dan dianalisis di dalam perisian SPSS V. 23. Analisis yang digunakan dan dipersembahkan ialah analisis regresi linear mudah. Keputusan yang diperolehi akan menggambarkan sejauhmana hubungan dan pengaruh antara dua Matematik peringkat sekolah menengah dengan keputusan Matematik Kejuruteraan 2 di politeknik.

\section{Populasi Kajian}

Kajian yang ini melibatkan pengumpulan data pelajar sebanyak 2442 orang yangdiperolehi daripada Unit Peperiksaan PSMZA. Merujuk kepada jadual 3.1, data yang digunakan ini adalah data yang terdiri daripada markahpencapaian Matematik moden dan Matematik tambahan semasa SPM . Manakala untuk pencapaian di peringkat politeknik pula keputusan peperiksaan akhir DBM2013 bagi Disember 2016, Disember 2017, Jun 2016 dan Jun 2017 diambil. Ia melibatkan ketiga-tiga jabatan iaitu Jabatan Kejuruteraan Awam, Jabatan Kejurutaraan Elektrik dan Jabatan Kejuruteraan Makanikal. Sesi Jun dan Disember diasingkan kerana berdasarkan kepada rekod pengambilan, pelajar yang memasuki sesi 
Jun adalah pelajar yang baru menghabiskan alam persekolahan mereka, manakala sesi disember pula adalah pelajar yang lebih berusia dan agak lama telah meninggalkan semua yang mereka telah pelajari. Dengan kata lain, pelajar pada sesi Jun lebih muda dan masih baharu meninggalkan matematik yang mereka telah pelajari.

Jadual1 : Bilangan pelajar semester dua di PSMZA yang mengambil kursus Matematik Kejuruteraan 2 untuk sesi Disember 2016, Disember 2017, Jun 2016 dan Jun 2017.

\begin{tabular}{llllll}
\hline \multirow{2}{*}{ Sesi } & Matapelajaran & JKA & JKE & JKM & Jumlah \\
\hline \multirow{2}{*}{ Jun 2016 \& 2017} & Matematik Tambahan & 76 & 83 & 109 & 268 \\
& Matematik Moden & 133 & 176 & 219 & 528 \\
& Matematik Tambahan & 269 & 141 & 164 & 574 \\
Disember 2016 \& 2017 & Matematik Moden & 406 & 648 & 860 & 1914 \\
& & & & & \\
\hline
\end{tabular}

Jumlah populasi

\section{Analisis kajian}

Data yang telah diperolehi dianalisis menggunakan perisian SPSS V. 23. Analisis yang digunakan ialah regrasi linear mudah. Analisis regresi linear mudah yang bertujuan untuk melihat sejauhmana hubungan atau pengaruh pembolehubah bebas atau tidak bersandar terhadap pembolehubah bersandar. Regresi digunakan untuk mengenalpasti perubahan yang menyumbang kepada perubahan dalam suatu pembolehubah bersandar (Chua Yan Piaw, 2013). Hubungan dan pengaruh antara Matematik tambahan dan Matematik moden dengan Matematik 2 dikenalpasti menggunakan $R$ square dan nilai Beta. Sepertimana dinyatakan oleh Rusinah Joned dan Sudirman Asmadi (2003) iaitu bagi analisis regresi linear mudah, nilai R Square digunakan. Hasil analisis yang diperolehi dapat memberi gambaran mengenai persepsi bahawa pelajar yang mengambil Matematik tambahan akan memperolehi keputusan yang lebih baik dalam kursus DBM2013 di politeknik.

\section{DAPATAN KAJIAN DAN PERBINCANGAN}

\section{Dapatan Kajian daripada Analisa regrasi linear berganda}

Analisa regrasi linear mudah bertujuan untuk mengetahui pengaruh pembolehubah yang tidak bersandar iaitu Matematik tambahan dan Matematik moden dengan pembolehubah bersandar iaitu pencapaian pelajar dalam Matematik Kejuruteraan 2. Analisis ini menggunakan aras signifikan, R square dan beta iaitu jika nilai signifikan $\mathrm{p}<0.05$ maka terdapat hubungan yang signifikan di antara dua pembolehubah tersebut.

Jadual 2 : Analisis Regresi Matematik Tambahan Dan Matematik Moden Terhadap Pencapaian Matematik Kejuruteraan 2 Bagi Pelajar Sesi Jun 2016 Dan Jun 2017 


\begin{tabular}{lccc}
\hline Pembolehubah & beta & R Square & P \\
\hline Matematik Tambahan & 0.500 & 0.248 & 0.000 \\
& & & \\
Matematik Moden & 0.469 & 0.220 & 0.000
\end{tabular}

Jadual 2 menunjukkan analisis regrasi Matematik tambahan dan matematik moden terhadap pencapaian Matematik Kejuruteraan 2 bagi sesi Jun 2016 dan Jun 2017. Hasil analisis tersebut menunjukkan terdapat hubungan yang signifikan bagi Matematik tambahan dan Matematik moden dengan pencapaian Matematik Kejuruteraan 2. Ini kerana nilai $\mathrm{p}=0.000$ bawah daripada nilai alpha 0.05 . Didapati juga pembolehubah bebas Matematik tambahan menunjukkan pengaruh yang lebih kuat dalam pencapaian Matematik Kejuruteraan 2 berbanding Matematik moden iaitu nilai beta, $B=0.500$ dengan menyumbang sebanyak $25 \%$ berdasarkan kepada nilai $\mathrm{R}$ Square yang diperolehi. Ini menunjukkan bahawa Matematik tambahan mempunyai pengaruh yang lebih kuat terhadap pencapaian pelajar dalam Matematik Kejuruteraan 2 di politeknik.

Jadual 3 : Analisis Regresi Matematik Tambahan Dan Matematik Moden Terhadap Pencapaian Matematik Kejuruteraan 2 Bagi Pelajar Sesi Dis 2016 Dan Dis 2017

\begin{tabular}{lccc}
\hline Pembolehubah & beta & R Square & P \\
\hline Matematik Tambahan & 0.581 & 0.335 & 0.000
\end{tabular}

Matematik Moden

0.400

0.159

0.000

Jadual 3 menunjukkan analisis regrasi Matematik tambahan dan matematik moden terhadap pencapaian Matematik Kejuruteraan 2 bagi sesi Disember 2016 dan Disember 2017. Keputusan analisis merumuskan bahawa terdapat terdapat hubungan yang signifikan bagi Matematik tambahan dan Matematik moden dengan pencapaian Matematik Kejuruteraan 2. Ini kerana nilai p=0.000 bawah daripada nilai alpha 0.05. namun begitu, didapati pembolehubah bebas Matematik tambahan menunjukkan pengaruh yang lebih kuat dalam pencapaian Matematik Kejuruteraan 2 berbanding Matematik moden iaitu nilai beta, $\mathrm{B}=0.581$ dengan peratusan pengaruh yang lebih tinggi iaitu $33 \%$ berdasarkan nilai R Square. Ini menunjukkan bahawa Matematik tambahan mempunyai pengaruh yang lebih kuat terhadap pencapaian pelajar dalam Matematik Kejuruteraan 2 di politeknik berbanding dengan Matematik moden.

Oleh itu, berdasarkan hasil yang diperolehi pada jadual 4.3 dan jadual 4.4 dapat disimpulkan bahawa pelajar yang mengambil matapelajaran Matematik tambahan semasa sekolah menengah lebih cenderung untuk mendapat skor yang lebih baik dalam Matematik Kejuruteraan 2 di politeknik berbanding dengan pelajar yang hanya mengambil matapelajaran Matematik moden sahaja. Namun begitu mungkin terdapat juga faktor-faktor lain yang boleh mempengaruhi pencapaian pelajar contohnya minat mereka terhadap Matematik, perekitaran dan motivasi daripada pensyarah dan rakan sebaya. 


\section{Perbincangan}

Matematik merupakan satu komponen yang penting dalam bidang Kejuruteraan, oleh itu asas yang kukuh dalam Matematik semasa alam persekolahan akan membantu pelajar tersebut mendapat keputusan yang cemerlang dalam matapelajaran ini apabila mereka memasuki institusi pengajian tinggi. Menurut Mohd Salleh Abu (1991), seseorang pelajar yang tidak menunjukkan konsep dan kemahiran Matematik akan menghadapi masalah pemahamaan dalam Matematik. Jika pelajar tidak dapat menguasai asas Matematik dengan baik kemungkinan mereka akan menghadapi masalah untuk terus menguasai konsep Matematik secara lebih mendalam. Pelajar yang tidak dapat menguasai konsep akan merasa Matematik sukar dan akan menurunkan motivasi mereka terhadap matapelajaran tersebut dan kemungkinan akan memberi kesan kepada pengajian mereka secara amnya.

Daripada analisis kajian ini, didapati terdapat hubungan positif yang signifikan dan sederhana antara pencapaian Matematik di peringkat sekolah menengah dengan pencapaian Matematik Kejuruteraan 2 di politeknik. Hasil analisis secara statistikal ini juga membuktikan bahawa tanggapan mengenai pencapaian Matematik tambahan akan mempengaruhi keputusan pelajar dalam Matematik Kejuruteraan 2 juga adalah benar. Sekiranya pelajar mendapat keputusan yang baik dalam matapelajarn Matematik tambahan, kemungkinan mereka juga akan memperolehi skor yang tinggi dalam matapelajaran tersebut di peringkat politeknik atau universiti. Ini kerana mereka telah pun mempunyai asas iaitu kalkulus yang turut dimasukkan dalam silibus Matematik Kejuruteraan 2.

Kajian yang dilakukan oleh Ahmad Fauzi, Norhayati dan Wong (2005) mendapati bahawa ada perhubungan yang kuat antara pencapaian pelajar dalam matapelajaran Matematik moden dan matemtik tambahan pada peringkat sijil pelajaran Malaysia (SPM) dengan pelajar di peringkat university bagi kursus kalkulus. Kajian ini disokong oleh Azhari Ahmad et al, (2017) yang menyatakan bahawa kursus Matematik pra tahun dan kursus Matematik awal dalam Kejuruteraan dan sains computer mempunyai hubungan positif yang signifikan dan nilai korelasi yang sangat kuat.

Secara keseluruhannya, dapatan kajian menunjukkan penguasaan Matematik semasa sekolah menengah sangat penting bagi membantu pelajar memperoleh keputusan yang baik dalam matapelajaran Matematik Kejuruteraan 2. Manakala daripada ujian regrasi ia menunjukkan bahawa Matematik tambahan pula menjadi peramal yang lebih kuat kepada kecemerlangan Matematik Kejuruteraan 2 berbanding Matematik moden. Ini disokong oleh kenyataan Wong Khoon Yoong (1987), kebolehan Matematik yang lebih tinggi (institusi pengajian tinggi) adalah bergantung kepada kebolehan yang lebih rendah (sekolah menengah), iaitu dalam bentuk hirarki. Ia turut dinyatakan dalam kajian Titi Khawa dan Bibi (2000) yang menyatakan bahawa pencapaian pelajar di peringkat SPM bagi matepelajarn fizik dan Matematik tambahan mempengaruhi pencapaian akademik mereka dalam bidang Kejuruteraan di peringkat diploma.

\section{KESIMPULAN}

Kesimpulannya, kajian ini perlu dijalankan dan penting bagi mengenalpasti permasalahan yang dihadapi oleh pelajar dalam kursus ini. Diharapkan hasil daripada kajian ini dapat mencari jalan penyelesaian bagi membantu meningkatkan kelulusan para pelajar dan meningkatkan keberkesanan proses pengajaran dan pembelajaran dalam matapelajaran Matematik Kejuruteraan 2 . Daripada hasil yang diperolehi dapat disimpulkan bahawa wujud hubungan yang signifikan antara pencapaian pelajar semasa sekolah menengah dengan keputusan akhir mereka di politeknik dan Matematik tambahan merupakan antara faktor yang penting dalam menentukan kecemerlangan pelajar dalam matapelajaran Matematik Kejuruteraan 2 di politeknik.

Sudah menjadi lumrah di dalam satu-satu kelas, terdapat sebahagian pelajar yang pintar, sederhana dan lemah. Walaupun pensyarah mempunyai kelulusan yang tinggi, kita tidak boleh menganggap pelajar mampu mengikuti apa yang kita ajar tanpa mengambil kira latar belakang mereka. Ada sesetengah pelajar, mereka mampu fokus di dalam kelas, manakala segelintir yang lain pula tidak dapat memberikan tumpuan yang sepenuhnya. Banyak faktor yang menyumbang kepada perkara ini antaranya latar belakang 
pelajar, cara pengajaran pensyarah, bahan P\&P yang digunakan dan juga persekitaran. Hasil daripada perbincangan dan kesimpulan yang telah dihuraikan, berikut adalah beberapa cadangan yang boleh dibuat penambahbaikan iaitu:

i. Pelbagai aktiviti pembelajaran perlu diterapkan supaya dapat menarik minat pelajar dalam usaha meningkatkan pencapaian mereka. Minat pelajar boleh dipupuk melalui pembelajaran berpusatkan pelajar seperti simulasi, pembelajaran koperatif, pembelajaran konstektual dan sebagainya. Pembelajaran berpusatkan pelajar menjadikan pelajar lebih aktif di dalam kelas dan berlaku penbelajaran secara dua hala. Kaedah ini akan membawa lebih kebaikan kerana pelajar dapat lebih memahami bahan pengajaran \& pembelajaran, memperoleh pemikiran kritkal dan meningkatkan kemahiran menyelesaikan masalah secara kreatif dan juga dapat meningkatkan keyakinan para pelajar.

ii. Pensyarah-pensyarah boleh memberikan pendedahan kepada para pelajar dengan situasi sebenar melalui program lawatan sambil belajar ke firma-firma berkaitan dan ke pusat sains agar kesedaran dan kefahaman dalam bidang yang dipelajari dapat diserapkan ke dalam jiwa pelajar dengan lebih berkesan.

iii. Pembelajaran secara interaktif melalui CIDOS yang telah dibangunkan di politeknik boleh digunakan secara optimum bagi menggalakkan penglibatan pelajar dengan pelajar atau antara pelajar dengan pensyarah secara aktif daam setiap aktiviti dan perbincangan dalam ruangan forum. Walaubagaimanapun, topik yang dibincangkan perlulah releven dengan proses pembelajaran mereka. Ini merupakan satu nilai tambah dalam proses pengajaran dan pembelajaran.

iv. Sebagai pensyarah yang bertanggungjawab terhadap pelaksanaan kursus Matematik Kejuruteraan, pensyarah hendaklah mengambil inisiatif mengatur program atau bengkel di peringkat jabatan khususnya. Sebagai contoh mengadakan bengkel kecemerlangan Matematik , explorace, sistem mentor, kelas pemulihan Matematik dan sebagainya. Melalui program ini pelajar akan didedahkan dengan pendekatan baru dalam pembelajaran.

v. Daripada dapatan kajian ini, kami mencadangkan supaya agar pihak pengambilan politeknik akan lebih peka terhadap kelayakan pelajar dengan menekankan pencapaian Matematik dan fizik SPM yang memberangsangkan memandangkan pelajar memerlukan asas tersebut semasa menyambung pengajian di politeknik.

vi. Pensyarah harus memperbaiki penggunaan bahan dalam pengajaran seperti mempelbagaikan alat bantu mengajar yan sesuai untuk meningkatkan keberkesanan pengajaran dan pembelajaran serta menarik minat murid. Teknologi Android boleh digunakan supaya pelajar boleh belajar dengan cepat dan mudah untuk mendapatkan maklumat walau di mana jua mereka berada.

vii. Kami mencadangkan pihak pengurusan boleh menambahkan tenaga pengajar daripada opsyen Matematik untuk menyampaikan ilmu kepada pelajar. Mereka perlu menguasai isi kandungan dalam Matematik \& sains serta perlu mempunyai pengetahuan yang cukup. Pensyarah mesti menunjukkan komitmen yang tinggi terhadap tugasnya dan sentiasa berusaha meningkatkan profesionalisme mereka dalam bidang Matematik.

\section{DAFTAR PUSTAKA}

Noraini Idris (2013). Penyelidikan Dalam Pendidikan. Selangor : Mc Graw Hill Education.

Chua Yan Piaw (2014). Asas statistik penylidikan Edisi ketiga. Selangor : Mc Graw Hill Education.

Rusinah Joned \& Sudirman Asmadi (2003). Modul latihan metodologi penyelidikan. Aplikasi statistic dan ethnograph untuk social sains. Mc Graw Hill Education.

Effandi Zakaria, Normalizam Mohd Zain, Nur Amalina Ahmad \& Ayu Erlina (2012). Mathematics Anxiety And Achievement Among Secondary School Students. American Journal of Applied Sciences 9 (11), 1828-1832.

Norziah Othman, Effandi Zakaria \& Zanaton Iksan. (2014). Nilai Dalam Pengajaran Matematik Di Institusi Pengajian Tinggi. e-Jurnal Penyelidikan dan Inovasi KUIS Jilid 1(II): 56-68. 
Siti Zaleha Binti Khalin.(2014). Kebimbangan Matematik Dan Hubungannya Dengan Pencapaian Pelajar Tingkatan Empat Di Daerah Perak Tengah.

KAE, W. J. (2010). Faktor-Faktor Yang Mempengaruhi Pembelajaran Matematik Tambahan Dalam Kalangan Pelajar Tingkatan Empat.

Siti Huzaifah Mohammad \& Nor Sharidah Mohd Roslan. 2017. Tahap Kebimbangan Matematik Dan Hubungannya Dengan Pencapaian Pelajar Di Politeknik Muadzam Shah, Pahang. e- Proceeding National Innovation and Invention Competition Through Exhibition 201, 1-11.

Norazlina Ahmad, Azman Talib. (2015). Hubungan Pencapaian Matematik Spm Terhadap Keputusan Matematik Kejuruteraan - Dbm1013 Dan Pencapaian HPNM Pelajar DET Di Politeknik Kota Kinabalu(October), 1-7.

Asyikin, S. N., Razali, M., Sufahani, S. F. \& Arbin, N. (2015). Pencapaian Kursus Matematik Dan Statistik Di Kalangan Pelajar Uthm: Faktor Mempengaruhi Dan Teknik Pengajaran Dan Pembelajaran Yang Lebih. Journal of techno social issue on society, technology \& Governance, 7(2), 39-50.

Safura Ahmad Sabri, Norziah Othman (2015). Teknik Pembelajaran Kalkulus Dalam Kalangan Pelajar Institusi Pengajian Tinggi 2015(May 2017), 403-412.

Sabri Ahmad, Tengku Zawawi Tengku Zainal, Aziz Omar (2006). Isu-isu Dalam Pendidikan Matematik. Utusan Publication, 19. 